\title{
Age-related reduction in the differential pathways involved in internal and external movement generation
}

\author{
S. Heuninckx, N. Wenderoth, S.P. Swinnen* \\ Motor Control Laboratory, Research Center for Movement Control and Neuroplasticity, Group Biomedical Sciences, K.U. Leuven, Belgium \\ Received 1 June 2007; received in revised form 21 February 2008; accepted 26 March 2008
}

\begin{abstract}
Age-related differences in regional brain activation during two different movement generation modes were examined. Old and young volunteers were scanned while performing cyclical hand-foot flexion-extension movements in the presence and the absence of augmented visual feedback, referring to external and internal movements generation, respectively. Performing the coordination task under both conditions resulted in the activation of two distinct neural networks in the young adults, i.e., the hMT/V5+, and parietal and premotor cortices were typically involved during the visually guided mode, whereas the supplementary motor area (SMA), cingulate motor area (CMA), frontal operculum (FO) and secondary somatosensory area (S2) were typically involved during internally guided movements. Remarkably, much less differentiation between both feedback dependent networks was observed in the seniors, i.e., they exhibited high activity in the SMA, CMA, FO and S2 during both modes, suggesting that the typical network differentiation was largely diminished. This is hypothesized to reflect a general increase in processing resources within areas contributing to motor control and associated sensory processing, supporting motor performance in the elderly.
\end{abstract}

(C) 2008 Elsevier Inc. All rights reserved.

Keywords: Aging; fMRI; Motor control; Interlimb coordination; Cyclical movement; Compensatory recruitment; Feedback; Internal and external movement generation

\section{Introduction}

It is well documented that normal aging is associated with deterioration in motor functioning (Seidler and Stelmach, 1995; Spirduso, 1982; Welford, 1988). In view of the current major demographic evolution of society with an increasing proportion of elderly persons, major socio-economic benefits are associated with maintaining and/or increasing their functional independence and comfort of living. This requires a deeper understanding of the processes of neural aging associated with control of movement. With the increasing availability of brain imaging technologies, such as blood-oxygen-level-dependent functional magnetic

\footnotetext{
* Corresponding author at: Laboratory of Motor Control, Research Center for Movement Control and Neuroplasticity, Group Biomedical Sciences, K.U. Leuven, Tervuursevest 101, B-3001 Heverlee, Belgium. Tel.: +32 163290 66; fax: +3216329197.

E-mail address: Stephan.Swinnen@faber.kuleuven.be (S.P. Swinnen).
}

resonance imaging (BOLD fMRI) and positron emission tomography (PET), aging research has primarily focused on the relationship between changes in behavior and brain function (for reviews, see Cabeza, 2001; Grady, 2000; Hedden and Gabrieli, 2004; Rajah and D'Esposito, 2005; Reuter-Lorenz, 2002; Reuter-Lorenz and Lustig, 2005; Ward, 2006).

Recent motor systems research has revealed that seniors exhibit stronger brain activation than younger controls during the execution of various motor tasks, even when behavioral performance is matched. Old subjects activate either the same areas as their younger counterparts, but to a larger extent, or they activate additional areas that are not observed in the young subjects (Heuninckx et al., 2005, 2008; Hutchinson et al., 2002; Mattay et al., 2002; Naccarato et al., 2006; Riecker et al., 2006; Ward and Frackowiak, 2003). Agerelated differences become more pronounced in complex motor tasks and usually refer to additional activation in brain regions involved in higher-order aspects of motor control, such as increased cognitive monitoring of performance and 
processing of somatosensory information (Heuninckx et al., 2005).

Here, we address for the first time age-related changes in brain activation in the context of two modes of movement generation that have dominated the field. With respect to the neural correlates of internally versus externally guided movements, Goldberg (1985) originally hypothesized that both movement generation modes have a separate anatomical basis. Later studies further scrutinized this hypothesis and showed that the cerebellum, parietal lobes and lateral premotor cortex dominate during externally guided movements, whereas supplementary motor area and basal ganglia activation would be prominent during internally guided movements (Passingham, 1997). Several neuroimaging studies have addressed this issue in adolescents and have largely supported this dissociation between both neural networks under various task conditions (e.g. Debaere et al., 2003; Deiber et al., 1999; Jenkins et al., 2000; Jueptner and Weiller, 1998; Ogawa et al., 2006; Rao et al., 1997; Vaillancourt et al., 2003; van Donkelaar et al., 1999).

Using fMRI, the present study addressed age-related differences in regional brain activation during both aforementioned movement generation modes, i.e., old and young adults performed continuous hand-foot coordination patterns in the presence and absence of augmented visual feedback about motor task performance during scanning. In the visual feedback condition, subjects received concurrent visual information during movement performance, which could be used to guide and correct the motor response on line (externally guided movements). In the condition without visual feedback, movements were performed in the absence of any external guidance, i.e., the movement was performed with higher reliance on an internal representation and was solely controlled by using somatosensory information (internally guided movements). Behavioral work has shown that provision of augmented visual feedback enhances motor skill acquisition and performance in adolescents (Lee et al., 1995; Swinnen et al., 1997a,b) as well as in elderly (Swinnen et al., 1998). Moreover, it has been demonstrated that elderly benefit more strongly from augmented visual feedback than younger controls (Seidler-Dobrin and Stelmach, 1998; Wishart et al., 2002; van Hedel and Dietz, 2004).

In spite of the vast amount of research on the aforementioned dissociation between externally and internally guided movement modes, no studies have so far investigated agerelated alterations in these networks. The following specific questions were addressed. First, we investigated whether the previously observed clear dissociation between both neural networks in adolescents, was also evident in elderly. In view of the aforementioned age-related increase in brain activation patterns during motor performance, we hypothesized that this functional subdivision would fade in the older adults, resulting in increased overlap between both networks. Second, we investigated whether the assumed overlap in the elderly group was a consequence of recruitment of regions during externally guided movements that were typically associated with internally guided movements in the young group, or vice versa. Finally, we explored whether the age-related changes in brain activation were a consequence of a differential use and/or differential degree of feedback processing between younger and older adults. To the best of our knowledge, these questions have not yet been addressed in the literature.

\section{Methods}

\subsection{Participants}

Twenty-four volunteers participated in this study, including 12 young adults (mean age, 23.5 years; range, 21-27 years; 9 women and 3 men) and 12 older adults (mean age, 66.9 years; range, $63-73$ years; 5 women and 7 men). All participants had normal or corrected to normal vision, and were right-handed, as assessed by the Edinburgh Handedness Inventory (Oldfield, 1971). None reported a history of neurological disease or sensorimotor dysfunctions or were taking psycho- or vasoactive medication. General cognitive functions were assessed using the Mini Mental State Examination (Folstein et al., 1975). All participants scored within normal limits (score $\geq 26$ ). Participants were informed about the experimental procedures and provided written informed consent. The informed consent and the study design were approved by the local Ethics Committee of Biomedical Research at K.U.Leuven, in accordance with the ethical standards laid down in the 1964 Declaration of Helsinki.

\subsection{Experimental design}

\subsubsection{Experimental setup}

Participants lay supine inside the scanner. The lower legs were supported by a cushion to ensure free ankle rotation. The right arm was extended along the trunk and the distal part of the arm was supported to enable free movements of the wrist. A bite-bar was used to minimize head motion. In this position, subjects looked at a screen (at a distance of $36 \mathrm{~cm}$ from their eyes) via a mirror. Visual information was projected onto the screen by means of a Barco (Kortrijk, Belgium) 6400i liquid crystal display projector $(1024 \times 768$ pixels; $60 \mathrm{~Hz})$. This setup was used for two purposes: during the first $2.5 \mathrm{~s}$ of each block, the subjects were instructed about the actual condition by showing a visual template symbolizing the required motor task. Additionally, for some conditions, visual feedback was provided online, displaying the subjects' coordination performance by means of a Lissajous figure (see below). The right wrist and foot were positioned in a non-ferromagnetic wrist-hand and ankle-foot orthosis (made in-house), respectively, restricting the movements to flexions-extensions in the sagittal plane. The frictionless axis of the orthosis was aligned with the anatomical axis of the joint such that movements were not hindered. Angular displacements of the joints were registered by means of high precision shaft encoders (HP, 4096 pulses per revolution, sampled at $100 \mathrm{~Hz}$ ), fixed 
to the movement axis of the orthosis. This unique nonferromagnetic kinematic registration device enabled us to register movements during brain scanning and to provide feedback projection of the movements in real-time.

\subsubsection{Task}

Subjects performed two different hand-foot coordination patterns, i.e., isodirectional (ISODIR) and non-isodirectional (NONISODIR). The ISODIR coordination pattern required rhythmical flexion and extension of both limb segments moving in the same direction (i.e., hand flexion together with foot flexion) (Fig. 1A). During NONISODIR coordination, segments were moved in opposite directions (i.e., hand flexion combined with foot extension, or vice versa) (Fig. 1B). Previous work has shown convincingly that the ISODIR movements can be performed without much effort, whereas the NONISODIR coordination mode is more difficult and is produced with a lower degree of phase accuracy and stability (Baldissera et al., 1982; Carson et al., 1995; Swinnen et al., 1997a,b). Accordingly, the aforementioned conditions represented a gradient of complexity.

Subjects were to execute both the ISODIR and NONISODIR coordination mode according to an externally and internally guided mode. Due to the continuous nature of the motions, we prefer to use the term movement guidance instead of generation (which is more appropriate for discrete movements). For the internally guided condition, participants were required to produce the movements without any external (augmented) feedback and to look at a fixation cross which was displayed in front of them. For the externally guided mode, on-line visual feedback was provided on the screen, consisting of the orthogonal plotting of the right hand and foot displacements in the form of a moving dot on the screen. A correct performance of the coordination modes resulted in the production of a diagonal line on the screen, i.e., from the lower left to the upper right diagonal for the ISODIR pattern, and from the lower right to upper left diagonal for the NONISODIR coordination pattern (Fig. 1). In addition to these movement conditions, two rest conditions were added: (1) participants were required to keep their limbs still and to look at a fixation cross (baseline rest condition); (2) participants looked at a display, similar to the Lissajous feedback signal but without executing the movements. During the latter condition, subjects watched a visual feedback signal that had the same characteristics as during the movement conditions (luminance, speed, color, etc.) but did not represent an actual movement pattern in order to eliminate movement imagination processes. In summary, the six different task conditions presented during scanning were: (1) performing the isodirectional hand-foot coordination pattern without augmented visual feedback, i.e., internally guided coordination

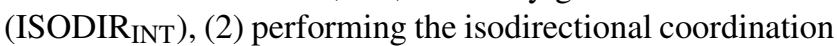
pattern in the presence of on-line, augmented visual feedback, i.e., externally guided coordination (ISODIR EXT $_{\text {), (3) }}$ performing the non-isodirectional coordination pattern in the absence of on-line visual feedback (NONISODIR INT $_{\text {), (4) }}$ performing the non-isodirectional coordination pattern in the presence of on-line visual feedback (NONISODIR EXT $_{\text {), (5) }}$ baseline rest condition without movement execution and no feedback signal (REST ${ }_{\text {INT }}$ ), (6) watching a feedback sig-
(A) Isodirectional hand-foot coordination
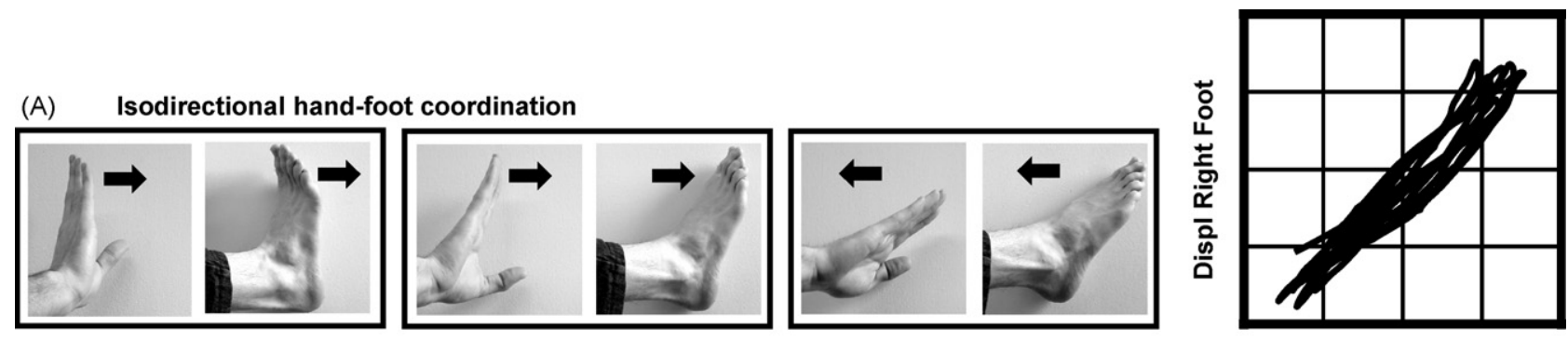

Displ Right Hand

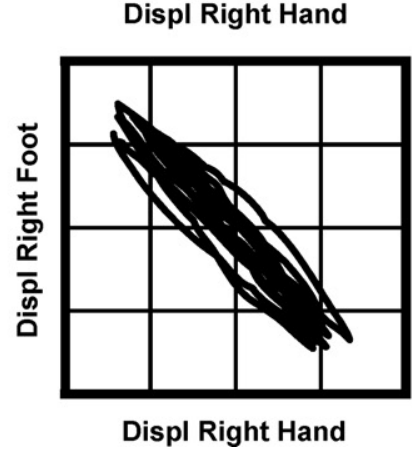

Displ Right Hand

(B) Nonisodirectional hand-foot coordination
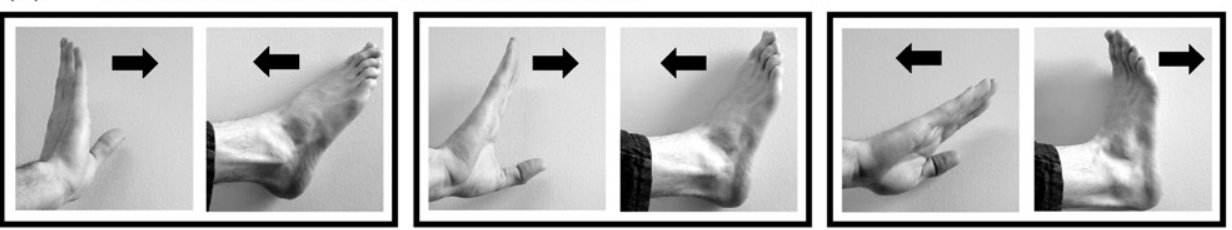

Fig. 1. Schematic representation of the two ipsilateral hand-foot coordination tasks. (A) During ISODIR coordination both limb segments are moved in the same direction. (B) During NONISODIR coordination both limb segments are moved in opposite directions. During the externally guided conditions, on-line visual feedback was provided on the screen, consisting of an orthogonal plot of the right hand and foot displacements. A correct performance of the coordination modes resulted in the production of a diagonal line on the screen, i.e., from the lower left to the upper right diagonal for the ISODIR pattern (A), and from the lower right to the upper left diagonal for the NONISODIR coordination pattern (B). 
nal without movement execution (REST $\mathrm{EXT}_{\mathrm{T}}$ ). By including

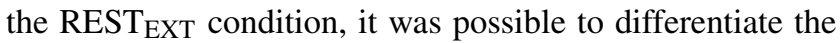
primary visual areas associated with viewing the visual feedback signal from the neural regions related to processing the visual feedback signal for the purpose of the control of limb movements.

To equate difficulty levels between groups, each subject was allowed to perform both coordination modes at a preferred cycling frequency. However, participants were instructed and trained to maintain the same rhythm across all movement conditions.

Prior to the experimental session, 45-min of practice was provided in a dummy-scanner to ensure correct performance. Both the ISODIR and NONISODIR coordination patterns were trained with and without augmented visual feedback (nine practice trials for each condition). For all four movement conditions, participants were trained to move their hand and foot with amplitudes ranging between $40^{\circ}$ and $60^{\circ}$. Additionally, subjects were trained to produce all four movement conditions at the same cycling frequency. Finally, the subjects were trained to restrict their movements to the right wrist and foot and to keep the other segments still.

\subsubsection{Scanning procedure}

The MRI images were acquired in a 3-T Intera MR scanner (Philips, Best, Netherlands), using a six element SENSE head coil (MRI Devices Corp., Waukesha. WI). Five functional time series were performed. Each time series consisted of 126 whole brain gradient-echo echoplanar images $(\mathrm{EPI})(\mathrm{TR} / \mathrm{TE}=3000 / 33 \mathrm{~ms}$, field of view $=230 \mathrm{~mm}$, matrix $=112 \times 112$, slice thickness $=4.0 \mathrm{~mm}$, interslice gap $=0.4 \mathrm{~mm}, 34$ sagittal slices, SENSE factor $=2$ ). Each time series consisted of three blocks of the six task conditions. Each condition lasted $21 \mathrm{~s}$ (corresponding to seven whole brain images) and was triggered by a visual template which was visible for $2.5 \mathrm{~s}$, displaying the task to be performed. The six different task conditions were randomized across runs and the runs were randomized across subjects. Following each time series, 3 min rest periods were provided. Each scanning session ended with the acquisition of a 3D SENSE high resolution T1-weighted image $(\mathrm{TR} / \mathrm{TE}=9.68 / 4.6 \mathrm{~ms}$, $\mathrm{TI}=1100 \mathrm{~ms}$, field of view $=250 \mathrm{~mm}$, matrix $=256 \times 256$, slice thickness $=1.2 \mathrm{~mm}, 182$ slices, SENSE factor $=2$ ) for anatomical detail.

\subsection{Data analyses}

\subsubsection{Kinematic analysis}

The coordination between the limb segments was assessed by means of a relative phase measure, i.e., the subtraction of the phase angles of each limb according to the formula $\Phi=\theta_{\mathrm{w}}-\theta_{\mathrm{f}}=\tan ^{-1}\left[\left(\mathrm{~d} X_{\mathrm{w}} / \mathrm{d} t\right) / X_{\mathrm{w}}\right]-\tan ^{-1}\left[\left(\mathrm{~d} X_{\mathrm{f}} / \mathrm{d} t\right) / X_{\mathrm{f}}\right]$, whereby $\mathrm{w}$ and $\mathrm{f}$ denotes wrist and foot, respectively; $\theta_{\mathrm{w}}$ refers to the phase of the wrist movement at each sample, $X_{\mathrm{w}}$ is the position of the wrist after rescaling to the interval $[-1,1]$ for each cycle of oscillation, and $\mathrm{d} X_{\mathrm{w}} / \mathrm{d} t$ is the normalized instantaneous velocity. Absolute deviations from the target relative phase (i.e., $0^{\circ}$ and $180^{\circ}$ for ISODIR and NONISODIR coordination, respectively) were calculated to obtain a measure of relative phase accuracy (phase error) (for similar procedures see, Heuninckx et al., 2005; Swinnen et al., 1997a,b). The standard deviation (S.D.) of relative phase was used as an estimate of movement pattern stability.

In addition to the relative phase measures, spatial and temporal parameters of the limb movements were quantified, i.e., amplitude and cycle duration. The spatial measure consisted of the absolute value of the peak-to-peak amplitude for each individual cycle. Cycle duration was defined as the time that elapsed between successive peak extension positions.

For the statistical analysis, the above parameters were determined for each movement condition and subsequently averaged across repetitions and runs. The statistical analysis of all the aforementioned behavioral parameters consisted of a $2 \times 2 \times 2($ Group $\times$ Coordination Mode $\times$ Feedback Mode $)$ analysis of variance for repeated measures (ANOVA) with the between factor Group (Young, Old), and the within factors Coordination Mode (ISODIR, NONISODIR) and Feedback Mode (EXT, INT). The $\alpha$-level of significance was set to $\alpha=0.05$.

\subsubsection{Imaging analysis}

Imaging Data were analyzed with SPM2 (Wellcome Department of Imaging Neuroscience, London, UK), implemented in Matlab 6.5 (The Mathworks Inc.). For each subject, all EPI volumes were realigned to the first volume of the first time series and a mean image of the realigned volumes was created. This mean image was smoothed with a Gaussian kernel of $6 \mathrm{~mm}$ full width at half maximum (FWHM) and co-registered to the anatomical T1-weighted image. To normalize the anatomical image as well as the EPIs to a standard reference system (Talairach and Tournoux, 1988), the following procedure was applied. First, the anatomical image as well as a representative template image (Montreal Neurological Institute, MNI), were segmented into gray matter, white matter and cerebrospinal fluids. Then the anatomical gray matter image was smoothed (6 mm FWHM) and normalized to the gray matter of the MNI brain. Subsequently, the derived normalization parameters were applied to the EPI images, which were subsampled to a voxel size of $2 \mathrm{~mm} \times 2 \mathrm{~mm} \times 2 \mathrm{~mm}$ and smoothed with a Gaussian kernel of $10 \mathrm{~mm}$ FWHM.

All statistical analyses were performed in the context of the General Linear Model (Friston et al., 1995a, 1995b). Each condition was modeled using a boxcar function convolved with the SPM2 haemodynamic response function. The time series in each voxel were high pass filtered at $0.004 \mathrm{~Hz}$ (corresponding to a period of $252 \mathrm{~s}$ ) to remove low frequency drifts. Additionally, movement parameters derived from realignment were added as covariates of no interest to correct for confounding effects induced by head movement. Contrasts of interest were first estimated for each subject individually 
(averaging activation across runs) and then subjected to a second level random effects analysis.

\subsubsection{Within-group contrasts. In a first step, within-group} activations were calculated to establish typical networks for externally and internally guided coordination within each age group. We examined (1) the brain regions that were similarly activated during the externally and internally guided mode and (2) the brain regions that were activated during externally guided over and above internally guided coordination, and vice versa. To identify regions similarly activated in both groups, the following conjunc-

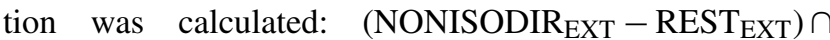
(NONISODIR INT - REST $_{\text {INT }}$ ). Statistically, the conjunction null hypothesis was tested in accordance to the method suggested by Nichols et al. (2005). A positive conjunction test implies that a given region is significantly activated during each feedback condition. Then, we created a mask confined to the conjoint areas and performed, within this mask, a $t$-test comparing the internally versus externally guided coordination modes. Areas which differed significantly between both conditions were not considered to be similarly activated. In a second step, we investigated which areas were active during externally guided over and above internally guided coordination by calculating the following contrast: (NONISODIR EXT $_{-}$ REST $\left._{\text {EXT }}\right)>\left(\right.$ NONISODIR $_{\text {INT }}-$ REST $\left._{\text {INT }}\right)$. In a final step, regions active during internally guided over and above externally guided coordination were studied by calculating the following contrast: (NONISODIR INT $_{-}$ REST $\left._{\text {INT }}\right)>\left(\right.$ NONISODIR $_{\text {EXT }}-$ REST $\left._{\text {EXT }}\right)$. The same analyses were applied with respect to the ISODIR coordination mode.

For all contrasts, a false discovery rate (FDR) correction was applied, ensuring an overall $p<0.01$, i.e. $t>4.00$. The FDR correction was preferred above the family wise error correction as the former correction method is more sensitive (Genovese et al., 2002). The minimum cluster size was arbitrarily set to 10 voxels.
2.3.2.2. Between-group comparisons. Between-group differences during the performance of externally versus internally guided coordination, were statistically tested by means of independent $t$-tests. The following interactions were calculated: (1) [(NONISODIR EXT $_{\left.- \text {REST }_{\text {EXT }}\right)>}$ $\left(\right.$ NONISODIR $_{\text {INT }}-$ REST $\left.\left._{\text {INT }}\right)\right]_{\text {old }}$ versus [(NONISOD$\left.\left.\mathrm{IR}_{\text {EXT }}-\mathrm{REST}_{\mathrm{EXT}}\right)>\left(\mathrm{NONISODIR}_{\mathrm{INT}}-\mathrm{REST}_{\mathrm{INT}}\right)\right]_{\text {young }}$ to identify group differences for areas that were more activated during the externally guided than during the internally guided coordination mode, and (2) [(NONISODIR INT $_{-}$ REST $\left._{\text {INT }}\right)>\left(\right.$ NONISODIR $_{\text {EXT }}-$ REST $\left.\left._{\text {EXT }}\right)\right]_{\text {old }}$ versus $\left[\left(\right.\right.$ NONISODIR $_{\text {INT }}-$ REST $\left._{\text {INT }}\right)>\left(\right.$ NONISODIR $_{\text {EXT }}-$

REST $\left.\left._{\text {EXT }}\right)\right]_{\text {young }}$ to identify group differences for areas that were more activated during the internally guided than during the externally guided coordination mode. The results of these $t$-tests were thresholded at $p<0.001$ uncorrected for multiple comparisons and, subsequently, small volume corrections were applied (sphere of $8 \mathrm{~mm}$ diameter, FDR, $p<0.05$, $t>2.17$ ) to those brain areas which were shown previously (e.g. Debaere et al., 2003; Deiber et al., 1999; Ogawa et al., 2006; van Donkelaar et al., 1999) to be specifically activated during externally versus internally guided movements, i.e., the cerebellum, parietal lobes and dorsal and ventral premotor cortex extending to the frontal operculum for the externally guided movements, and in the basal ganglia, and midline areas (supplementary motor area and cingulate motor area) for the internally guided motor areas. The small volume corrections were applied around those activation maxima which were shown in the within-group analyses to be specifically activated by externally versus internally guided movements. Identical analyses as described above were also performed for the ISODIR coordination mode.

\section{Results}

\subsection{Kinematic data}

As expected, the analysis of relative phase error (coordination accuracy) and the standard deviation (S.D.)

Table 1

Kinematic data

\begin{tabular}{|c|c|c|c|c|}
\hline & \multicolumn{2}{|l|}{ Young } & \multicolumn{2}{|l|}{ Old } \\
\hline & NON-FB & FB & NON-FB & FB \\
\hline \multicolumn{5}{|c|}{ A. NONISODIR } \\
\hline \multicolumn{5}{|c|}{ Relative phase measures } \\
\hline A.E. & $17.4^{\circ}\left(3.6^{\circ}\right)$ & $14.5^{\circ}\left(3.1^{\circ}\right)$ & $17.7^{\circ}\left(4.3^{\circ}\right)$ & $15.4^{\circ}\left(3.1^{\circ}\right)$ \\
\hline S.D. & $16.0^{\circ}\left(2.4^{\circ}\right)$ & $13.6^{\circ}\left(2.3^{\circ}\right)$ & $18.5^{\circ}\left(3.4^{\circ}\right)$ & $15.5^{\circ}\left(3.0^{\circ}\right)$ \\
\hline Amplitude & $50.2^{\circ}\left(12.0^{\circ}\right)$ & $50.4^{\circ}\left(10.7^{\circ}\right)$ & $57.8^{\circ}\left(10.8^{\circ}\right)$ & $57.4^{\circ}\left(15.3^{\circ}\right)$ \\
\hline Cycle duration & $1134 \mathrm{~ms}(166 \mathrm{~ms})$ & $1144 \mathrm{~ms}(177 \mathrm{~ms})$ & $1378 \mathrm{~ms}(153 \mathrm{~ms})$ & $1380 \mathrm{~ms}(151 \mathrm{~ms})$ \\
\hline \multicolumn{5}{|l|}{ B. ISODIR } \\
\hline \multicolumn{5}{|c|}{ Relative phase measures } \\
\hline A.E. & $15.7^{\circ}\left(3.3^{\circ}\right)$ & $13.3^{\circ}\left(3.5^{\circ}\right)$ & $15.9^{\circ}\left(3.7^{\circ}\right)$ & $13.9^{\circ}\left(2.9^{\circ}\right)$ \\
\hline S.D. & $14.6^{\circ}\left(2.4^{\circ}\right)$ & $11.8^{\circ}\left(2.3^{\circ}\right)$ & $15.4^{\circ}\left(3.3^{\circ}\right)$ & $13.5^{\circ}\left(2.6^{\circ}\right)$ \\
\hline Amplitude & $49.3^{\circ}\left(12.5^{\circ}\right)$ & $50.4^{\circ}\left(11.3^{\circ}\right)$ & $56.1^{\circ}\left(15.5^{\circ}\right)$ & $53.4^{\circ}\left(14.0^{\circ}\right)$ \\
\hline Cycle duration & $1131 \mathrm{~ms}(176 \mathrm{~ms})$ & $1139 \mathrm{~ms}(171 \mathrm{~ms})$ & $1381 \mathrm{~ms}(184 \mathrm{~ms})$ & $1377 \mathrm{~ms}(192 \mathrm{~ms})$ \\
\hline
\end{tabular}

A.E. $=$ absolute error, S.D. $=$ standard deviation. 
of relative phase (coordination stability) revealed that both the ISODIR and NONISODIR coordination patterns were performed more accurately (ISODIR: $F(1,22)=28.29$, $p<0.001$; NONISODIR: $F(1,22)=47.6, p<0.001)$ and consistently (ISODIR: $F(1,22)=67.1, p<0.001$; NONISODIR: $F(1,22)=69.3, p<0.00001)$ with augmented visual feedback than without (Table 1). No significant differences between the old and young group were observed (accuracy: ISODIR: $F(1,22)=0.09, p=0.77$; NONISODIR: $F(1,22)=0.2, p=0.66$; stability: ISODIR: $F(1,22)=1.4$, $p=0.25$; NONISODIR: $F(1,22)=3.9,=0.06)($ Table 1$)$. As expected, the ISODIR coordination mode was performed with higher accuracy $[F(1,22)=36.7, p<0.001]$ and stability $[F(1,22)=70.9, p<0.001]$ than the NONISODIR coordination pattern (Table 1).

Movement amplitudes did not differ between groups (ISODIR: $\quad F(1,22)=0.84, \quad p=0.37$; NONISODIR: $F(1,22)=2.17, p=0.15$ ), feedback conditions (ISODIR: $F(1,22)=0.99, \quad p=0.33 ; \quad$ NONISODIR: $F(1,22)=0.003$, $p=0.95)$ and coordination modes $(F(1,22)=1.60, p=0.22)$ (Table 1).
To equate difficulty levels between both age groups, each subject was allowed to perform the coordination modes at the preferred cycling frequency. The cycle duration was significantly larger in the old as compared to the young group, both for the ISODIR $(F(1,22)=11.0, p<0.01)$ and NONISODIR $(F(1,22)=13.1, p<0.005)$ coordination mode (Table 1). No significant differences between feedback modes (ISODIR: $F(1,22)=0.69, p=0.69$; NONISODIR: $F(1,22)=1.70, p=0.21)$, and between coordination modes $(F(1,22)=0.08, p=0.78)$ were observed (Table 1$)$. This indicates that the old group performed the coordination patterns with a lower preferred cycling frequency than their younger counterparts, but that the same frequency was maintained across both feedback conditions and coordination modes.

\section{2. fMRI data}

We first studied possible differences in brain activation during the performance of the ISODIR and NONISODIR coordination pattern. However, in spite of the performance differences between the ISODIR and NONISODIR coor-

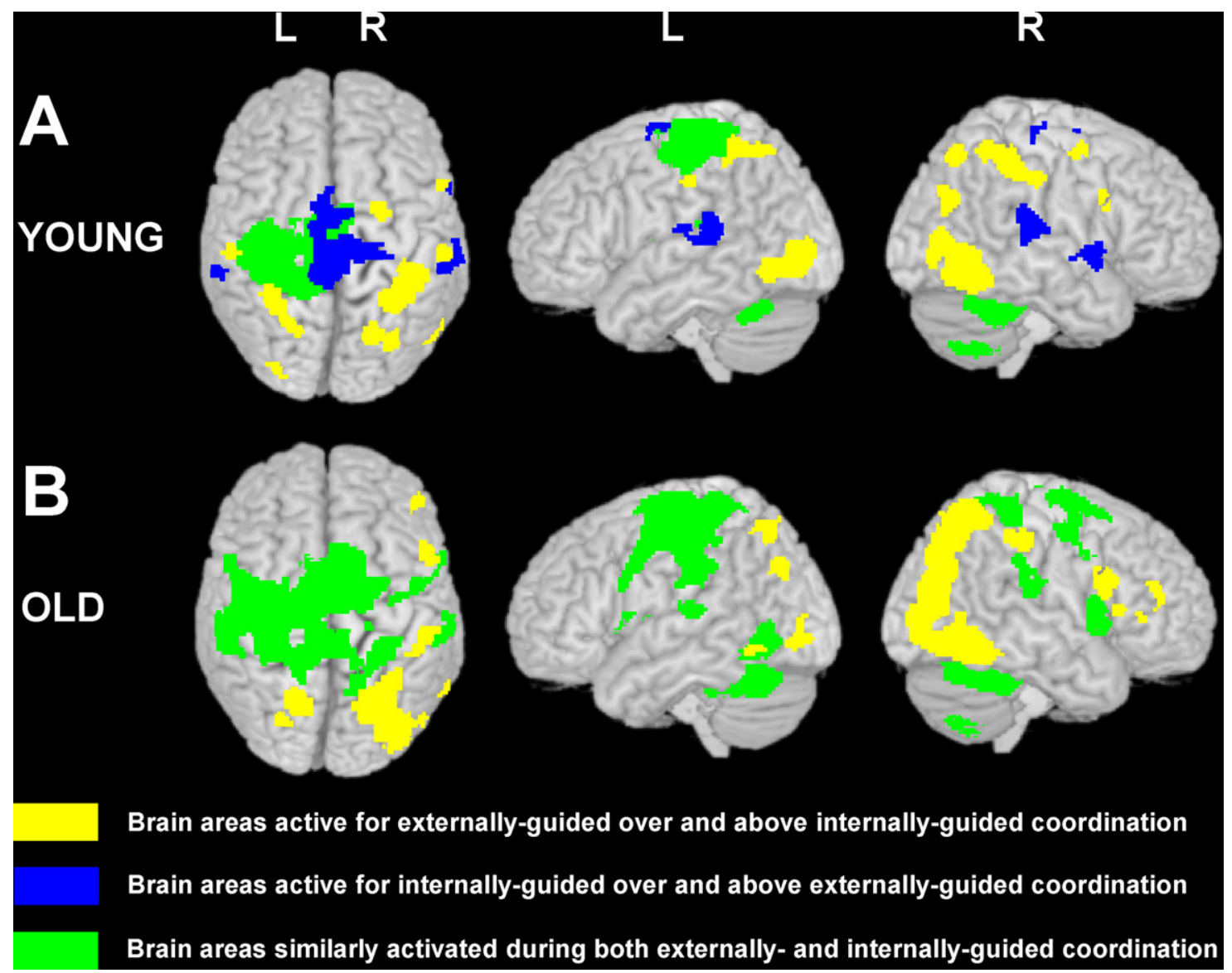

Fig. 2. Brain areas significantly ( $p<0.01$, corrected for multiple comparisons) more activated during externally than during internally guided coordination (yellow) and during internally than during externally guided coordination (blue), as well as areas similarly activated by both feedback conditions (green), overlaid on standard MNI renders, for both the young (A) and old (B) subjects; all SPMs are thresholded at $t=4.00$. L, left hemisphere, R, right hemisphere. (For interpretation of the references to color in this figure legend, the reader is referred to the web version of the article.) 
dination mode (see above), largely comparable results for both coordination modes were found. Previous studies (Heuninckx et al., 2005, 2008) have shown that the NONISO mode is a particularly sensitive comparison to discover age-related differences in brain activation. Therefore, we will focus on the results obtained for the NONISODIR coordination mode, and only shortly report about the ISODIR coordination pattern in a supplemental text document.

In a first step, within-group activations will be reported to establish typical networks for externally and internally guided coordination for each age group. In a second step, differences in brain activation between the both age groups during the performance of the externally versus internally guided coordination will be reported (between-group contrasts).

\subsubsection{Within-group contrasts}

Brain areas that were similarly activated during the externally and internally guided coordination mode (green) as well as brain areas active during externally guided over and above internally guided coordination (yellow) and areas active during internally guided coordination over and above externally guided coordination (blue), are shown in Fig. 2 for both the young (Fig. 2A) and old (Fig. 2B) subjects.

3.2.1.1. Within-group contrasts-Young adults. In the young subjects (Fig. 2A), similarly activated regions were mainly part of a general motor network typically observed during coordination tasks, including the contralateral primary sensorimotor cortex (SM1) and dorsal premotor cortex (PMd), and the cingulate motor area (CMA) as well as the thalamus, putamen and pallidum, the ipsilateral anterior and posterior cerebellum and the contralateral anterior cerebellum (for coordinates and $t$ values, see supplemental Table $1 *)$. However, a clear dissociation between the networks during the externally (yellow) versus internally guided (blue) movement conditions was evident in the young subjects. Significantly higher activation during externally than internally guided coordination was observed in the right superior frontal sulcus and inferior precentral sulcus, corresponding to the ventral part of the lateral premotor cortex (PMv), in the right intra-occipital sulcus, and bilaterally in the supramarginal gyri, near the junction of the postcentral and intraparietal sulci, corresponding to the anterior intraparietal area (AIPA), as well as bilaterally in the anterior and medial part of the dorsal intraparietal sulcus (ADIPS, MDIPS), and in a region on the border of the temporal and occipital cortex, corresponding to hMT/V5 (Table $1 *$ ). By contrast, significantly higher activation during internally than externally guided coordination was found in the right frontal operculum, in the left cingulate sulcus and posterior segment of the cingulate sulcus/gyrus, and bilaterally in the supplementary motor area (SMA), paracentral lobuli, and in the secondary somatosensory area (S2) (Table $1 *)$. In summary, young subjects activated largely dissociated networks for externally versus internally guided movements, which only overlapped within areas related to movement execution.

3.2.1.2. Within-group contrasts - old adults. In opposition to the young group, a much more extended network of brain regions that was similarly activated during both feedback conditions was evident in the old group, including SM1, SMA and CMA, left inferior precentral sulcus, superior parietal gyrus and supramarginal gyrus, the right PMd and right primary sensory cortex (S1), and near the midline to the anterior cingulate sulcus, pre-SMA, and paracentral lobuli (for coordinates and $t$ values, see supplemental Table $2 *$ ). Similar to the young subjects, i.e., significantly higher activation during externally guided than during internally guided coordination was observed in the left and right middle occipital gyri, hMT/V5, and ADIPS, and in the right inferior frontal gyrus, anterior insula, inferior frontal gyrus pars opercularis (IFGPO), MDIPS, AIPA and inferior occipital gyrus in the elderly group (Table $2 *$ ). By contrast, there were no areas specifically more activated during the internally guided than during the externally guided coordination mode. Instead, Fig. 2 clearly shows that areas, active during internally guided over and above externally guided coordination in the young group (blue), were also activated in the old group during externally guided coordination (green). In particular, brain regions active during internally guided coordination over and above externally guided coordination in the young group, were similarly recruited during the externally guided condition in the old group, such as the left and right insula, IFGPO, S2, left superior temporal gyrus, middle occipital gyrus, posterior cerebellum, the right postcentral sulcus, supramarginal gyrus and superior parietal gyrus (Table $2 *$ ).

Taken together, whereas the young subjects recruited two distinct brain networks during hand-foot coordination with and without visual feedback, much less differentiation between these feedback-dependent networks was observed in the elderly. These differences between the young and old subjects were studied in additional detail by means of statistical analyses directly contrasting brain activations for both feedback modes between both groups, discussed next.

\subsubsection{Between-group contrasts}

Between-group differences with respect to both feedback modes were statistically tested by means of independent $t$ tests.

\subsubsection{Interaction between Group and Feedback Mode - areas responding stronger to externally guided than to inter- nally guided coordination. The SPMs in Fig. 3 represent significant between-group differences in brain areas that are more activated during the externally guided than during the internally guided coordination mode. The bar plots display the estimated BOLD responses in the peak activation within a cluster, for the two different feedback modes, relative to the appropriately matched rest conditions, in the young (turquoise) and elderly (orange) subjects.}


(A)

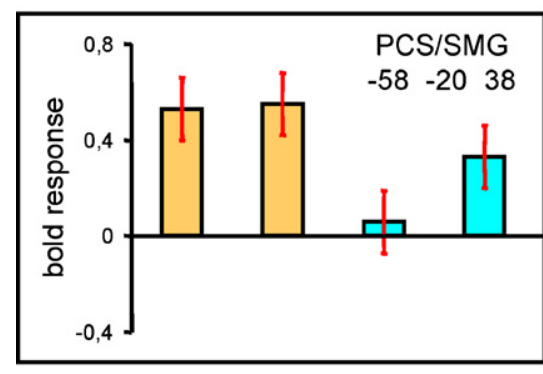

O-INT O-EXT Y-INT Y-EXT $(\text { EXT-INT) })_{\text {YOUNG }}>(\text { EXT-INT) })_{\text {OLD }}$
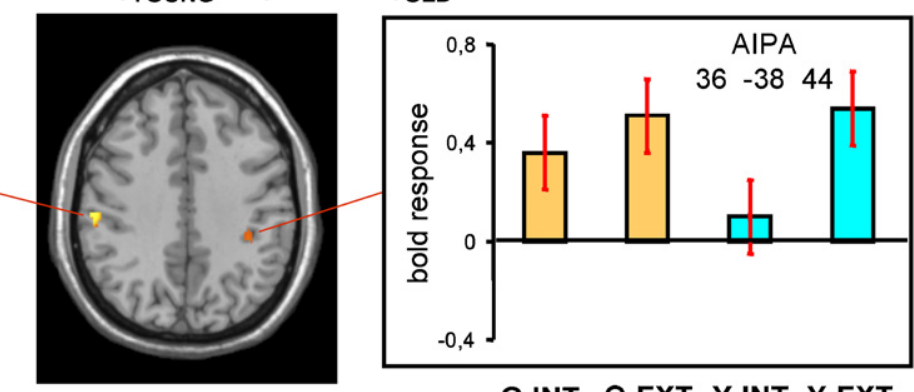

O-INT O-EXT Y-INT Y-EXT

(B)

$(\text { EXT-INT) })_{\text {OLD }}>(\text { EXT-INT) })_{\text {YOUNG }}$
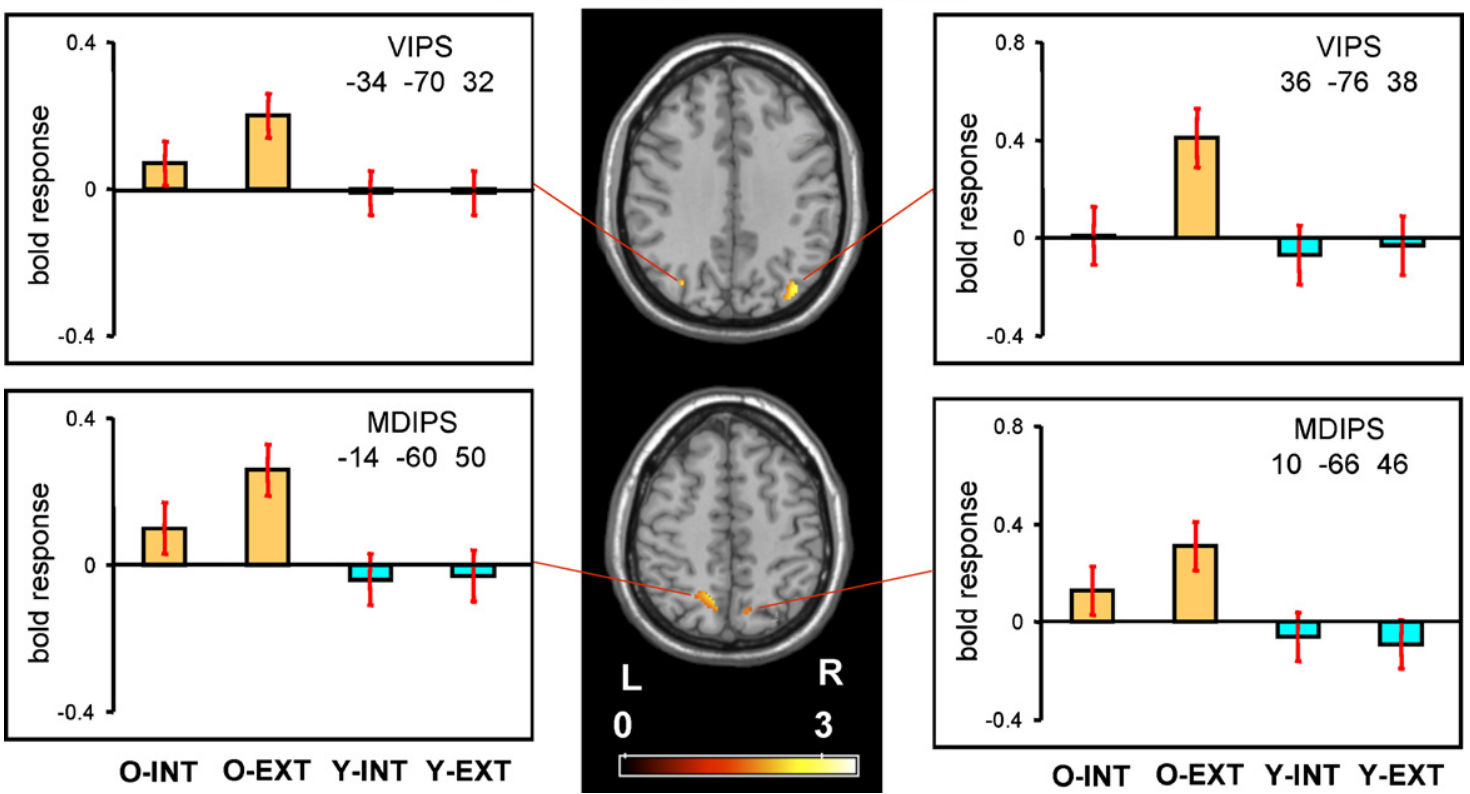

O-INT O-EXT Y-INT Y-EXT

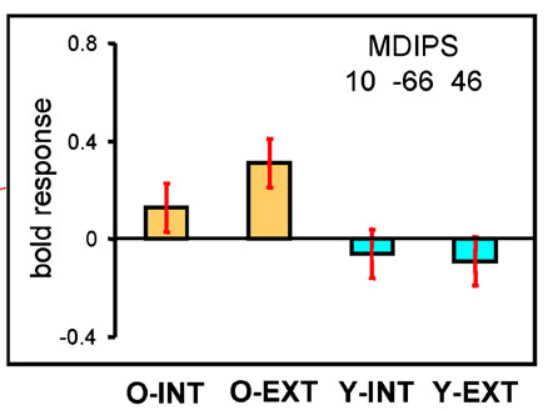

Fig. 3. Group $\times$ Feedback mode interactions: areas specifically involved in internal movement generation. SPMs representing (A) significantly larger BOLD response to internal than external movement generation (INT-EXT) in the young group as compared to the old group, and (B) significantly larger BOLD response to INT-EXT in the old group as compared to the young group. Significant voxels $(p<0.05, \mathrm{SVC}$ corrected) are indicated in the red spectrum and the height threshold is $t=2.17$. L, left hemisphere, R, right hemisphere; PCS/SMG, postcentral sulcus/supramarginal gyrus; AIPA, anterior intraparietal area; VIPS, ventral intraparietal sulcus; MDIPS, medial part of the intraparietal sulcus. The bar plots show the estimated BOLD responses, in the peak activation within a cluster, for both feedback modes, relative to the appropriate matched rest conditions, in the younger (turquoise) and elderly (orange) subjects: O-INT, old - internally guided; O-EXT, old - externally guided; Y-INT, young - internally guided; Y-EXT, young - externally guided. The error bars represent the standard error. (For interpretation of the references to color in this figure legend, the reader is referred to the web version of the article.)

We found a significant interaction between Group and Feedback Mode in the right AIPA, and in the left postcentral sulcus, near the AIPA (Fig. 3A, Table 2). Fig. 3A indicates that the young group (turquoise bars) exhibited a higher BOLD response during externally guided than during internally guided coordination in these regions, whereas the BOLD response was hardly modulated by feedback condition in the old group, remaining nearly equally high for both performance modes.

A similar interaction effect was found bilaterally in the MDIPS, and in regions located in the occipital part of the intraparietal sulcus, corresponding to the ventral intraparietal sulcus (VIPS) (Fig. 3B, Table 2). From the bar plots in Fig. 3B, it can be inferred that in these spots, the old group exhibited higher activations during the externally guided than during the internally guided mode, whereas these areas were hardly activated in the young group. Thus, the MDIPS and the VIPS areas were additionally activated by the elderly in the visual feedback condition but not by the young.

\subsubsection{Interaction between Group and Feedback Mode - areas responding more strongly to internally guided than to externally guided coordination. The SPMs in Fig. 4 repre- sent significant between-group differences in brain areas that are more activated during the internally guided than during the externally guided coordination mode. The bar plots in Fig. 4 display the estimated BOLD responses in the peak acti- vation within a cluster, for the two different feedback modes, relative to the appropriately matched rest conditions, in the younger (turquoise) and elderly (orange) subjects.}


$($ INT-EXT) YOUNG $>$ (INT-EXT) OLD
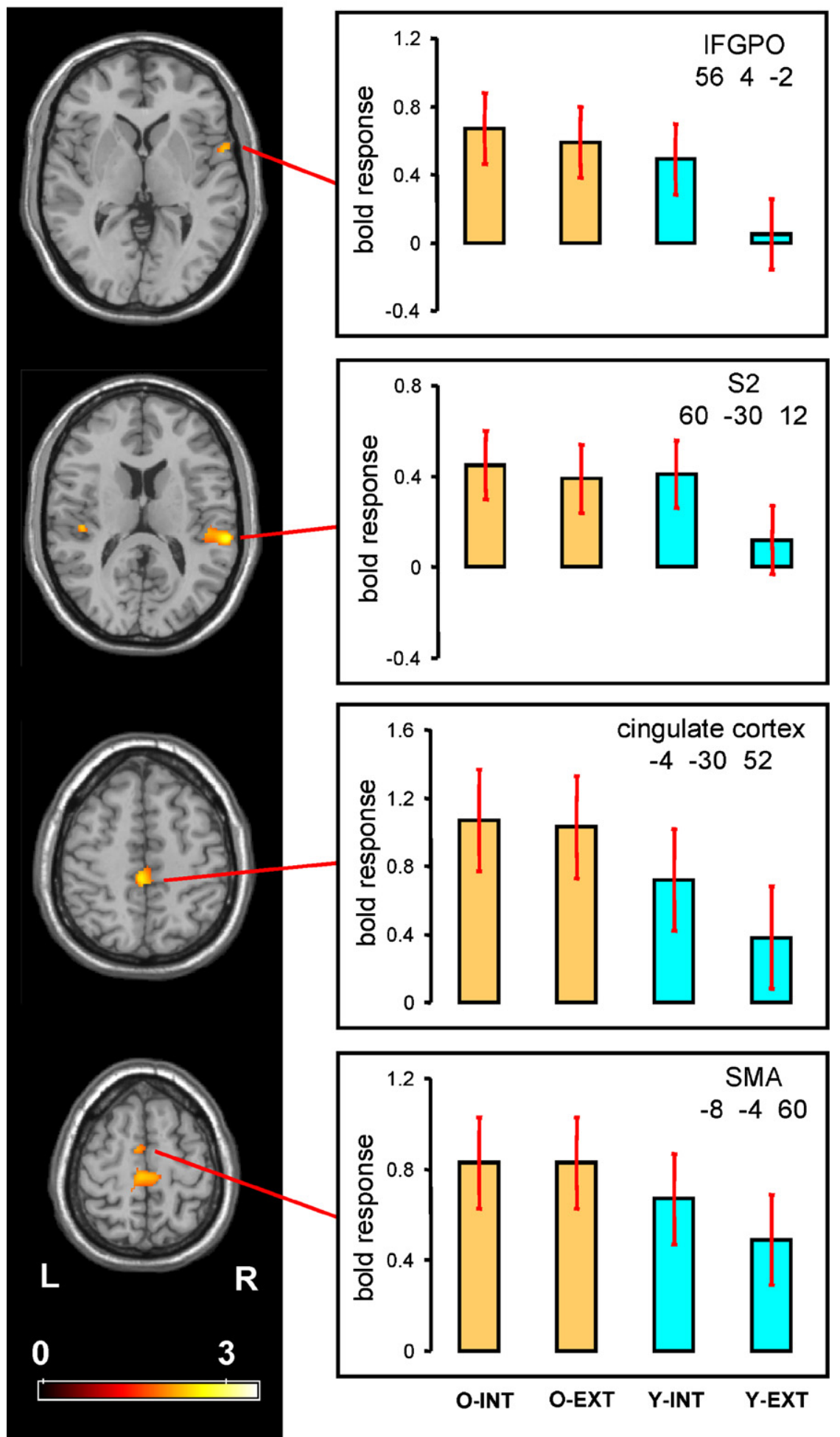

Fig. 4. Group $\times$ Feedback mode interactions: areas specifically involved in external movement generation. SPMs representing (A) significantly larger BOLD response to external than internal movement generation (EXT-INT) in the young group as compared to the old group, and (B) significantly larger BOLD response to EXT-INT in the old group as compared to the young group Significant voxels ( $p<0.05$, SVC corrected) are indicated in the red spectrum and the height threshold is $t=2.17$. L, left hemisphere, R, right hemisphere; IFGPO, inferior frontal gyrus pars opercularis; S2, secondary somatosensory area; SMA, supplementary motor area. The bar plots show the estimated BOLD responses, in the peak activation within a cluster, for both feedback modes, relative to the appropriately matched rest conditions, in the young (turquoise) and elderly (orange) subjects: O-INT, old - internally guided; O-EXT, old - externally guided; Y-INT, young - internally guided; Y-EXT, young - externally guided. The error bars represent the standard error. (For interpretation of the references to color in this figure legend, the reader is referred to the web version of the article.) 
Table 2

$t$-values and localizations (MNI coordinates) of activation peaks during non-isodirectional coordination showing significantly different activations between both age groups during externally guided versus internally guided coordination $\left(p_{\mathrm{SVC}}<0.05\right.$, corrected for multiple comparisons), resulting from the following contrasts: (1) $\left[\left(\text { NONISODIR }_{\text {EXT }}-\text { REST }_{\text {EXT }}\right)-\left(\text { NONISODIR }_{I N T}-\text { REST }_{\text {INT }}\right)\right]_{\text {young }}$ versus $\left[\left(\right.\right.$ NONISODIR $_{\text {EXT }}-$ REST $\left._{\text {EXT }}\right)$ $-\left(\right.$ NONISODIR $_{I N T}-$ REST $\left.\left._{I N T}\right)\right]_{\text {old }}$, and (2) $\left[\left(\text { NONISODIR }_{\text {EXT }}-\text { REST }_{\text {EXT }}\right)-\left(\text { NONISODIR }_{I N T}-\text { REST }_{\text {INT }}\right)\right]_{\text {old }}$ versus $\left[\left(\right.\right.$ NONISODIR $_{\text {EXT }}-$ REST $\left._{\text {EXT }}\right)$ - $\left(\right.$ NONISODIR $_{I N T}-$ REST $\left.\left._{\text {INT }}\right)\right]_{\text {young }}$ L, left hemisphere; R, right hemisphere; M, medial; AIPA, anterior intraparietal area; MDIPS, middle part of the dorsal intraparietal sulcus; VIPS, ventral part of the intraparietal sulcus; IFGPO, inferior frontal gyrus pars opercularis; SMA, supplementary motor area; S2, secondary somatosensory area

\begin{tabular}{|c|c|c|c|c|c|}
\hline Area activated & Side & $\mathrm{x}$ & $\mathrm{y}$ & $\mathrm{z}$ & $t$ value \\
\hline \multicolumn{6}{|l|}{$(\mathrm{EXT}-\mathrm{INT})_{\text {young }}>(\mathrm{EXT}-\mathrm{INT})_{\text {old }}$} \\
\hline Supramarginal gyrus /Postcentral sulcus & $\mathrm{L}$ & -58 & -20 & 38 & 2.95 \\
\hline AIPA & $\mathrm{R}$ & 36 & -38 & 44 & 2.93 \\
\hline \multicolumn{6}{|l|}{$(\mathrm{EXT}-\mathrm{INT})_{\mathrm{old}}>(\mathrm{EXT}-\mathrm{INT})_{\text {young }}$} \\
\hline \multirow[t]{2}{*}{ MDIPS } & $\mathrm{L}$ & -14 & -60 & 50 & 2.56 \\
\hline & $\mathrm{R}$ & 10 & -66 & 46 & 2.47 \\
\hline \multirow[t]{2}{*}{ VIPS } & $\mathrm{R}$ & 36 & -76 & 38 & 3.09 \\
\hline & $\mathrm{L}$ & -34 & -70 & 32 & 2.31 \\
\hline
\end{tabular}

Table 3

$t$-values and localizations (MNI coordinates) of activation peaks during non-isodirectional coordination showing significantly different activations between both age groups during internally guided versus externally guided coordination ( $p_{\mathrm{SVC}}$, corrected for multiple comparisons), resulting from the following contrasts: (1) $\left[\left(\text { NONISODIR }_{I N T}-\text { REST }_{\text {INT }}\right)-\left(\text { NONISODIR }_{\text {EXT }}-\text { REST }_{\text {EXT }}\right)\right]_{\text {young }}$ versus $\left[\left(\text { NONISODIR INT }_{\text {IN }}-\text { REST }_{\text {INT }}\right)-\left(\text { NONISODIR }_{\text {EXT }}-\text { REST }_{\text {EXT }}\right)\right]_{\text {old }}$, and (2) $\left[\left(\text { NONISODIR }_{I N T}-\text { REST }_{I N T}\right)-\left(\text { NONISODIR }_{\text {EXT }}-\text { REST }_{\text {EXT }}\right)\right]_{\text {old }}$ versus $\left[\left(\text { NONISODIR INT }_{\text {IN }}-\text { REST }_{I N T}\right)-\left(\text { NONISODIR }_{\text {EXT }}-\text { REST }_{\text {EXT }}\right)\right]_{\text {young }}$. L, left hemisphere; R, right hemisphere; M, medial; MDIPS, middle part of the dorsal intraparietal sulcus; VIPS, ventral part of the intraparietal sulcus; IFGPO, inferior frontal gyrus pars opercularis; SMA, supplementary motor area; S2, secondary somatosensory area

\begin{tabular}{|c|c|c|c|c|c|}
\hline Area activated & Side & $x$ & $y$ & $z$ & $t$ value \\
\hline \multicolumn{6}{|c|}{$(\mathrm{INT}-\mathrm{EXT})_{\text {young }}>(\mathrm{INT}-\mathrm{EXT})_{\text {old }}$} \\
\hline IFGPO & $\mathrm{R}$ & 56 & 4 & -2 & 2.42 \\
\hline SMA & $\mathrm{L} / \mathrm{M}$ & -8 & -4 & 60 & 2.17 \\
\hline Cingulate gyrus/sulcus & $\mathrm{L} / \mathrm{M}$ & -4 & -30 & 52 & 2.57 \\
\hline $\mathrm{S} 2$ & $\mathrm{R}$ & 60 & -30 & 12 & 2.82 \\
\hline$(\mathrm{INT}-\mathrm{EXT})_{\mathrm{old}}>(\mathrm{INT}-$ & & & & & \\
\hline
\end{tabular}

We found a significant interaction between Group and Feedback Mode in the right S2 and IFGPO, and near the midline in the SMA and cingulate gyrus and sulcus (Fig. 4, Table 3). From the bar plots in Fig. 4, it can be inferred that in all these areas, the young group (turquoise) showed higher activations during internally guided coordination than during externally guided coordination, whereas these areas were virtually equally activated during both modes in the old group (orange). There were no regions demonstrating higher activation during the internally guided than during the externally guided mode in the old as compared with the young group.

In summary, the interaction between Group and Feedback Mode provided additional confirmation that young subjects activated two largely dissociated networks for internal versus external movement guidance, whereas this distinction largely faded in the elderly. Nearly identical results were obtained for the ISODIR coordination task, providing additional support to the aforementioned analysis (see supplemental text document).

\section{Discussion}

The present study addressed for the first time age-related alterations in the neural basis of cyclical hand-foot coordi- nation, performed in the presence and absence of augmented visual feedback. The kinematic data revealed that the coordination patterns were performed with higher accuracy and stability during the presence of augmented visual feedback, as expected. Importantly, there were no significant differences in coordination accuracy and stability between age groups, suggesting that both groups performed the movement patterns equally successfully at the individually preferred cycling frequency. In addition, movement amplitudes were similar between both groups. All together, the kinematic results indicate that both groups performed the coordination patterns at comparable levels of difficulty. Consequently, brain activation differences between the two groups reflect age-related changes in the recruitment of specific neural networks, unconfounded by differences in task difficulty or motor performance. However, cycling frequency was significantly lower in the elderly than in the young subjects. Theoretically, this raises a methodological problem as different cycling frequencies between the age groups resulted in a different number of events within a block (i.e., the time period in which an experimental condition is presented within a scanning series). Roughly speaking, for an equivalent amount of underlying cortical activity, twice as many 'events' within the same block length may double the parameter estimate for that block. However, this potential methodological confound 
had only minor implications in the present study because (1) the young produced only about 2.75 cycles/block more than the elderly, and (2) the elderly exhibited more activity even though there were slightly less events in a block. Accordingly, our results may even underestimate the actually obtained overactivation in the elderly group.

Producing hand-foot movements with and without visual feedback resulted in the activation of two distinct neural networks in the young subjects. Conversely, much less differentiation between these feedback-dependent networks was observed in the elderly. Below, we will first discuss the networks for externally and internally guided movements in both age groups (Sections 4.1 and 4.2). Subsequently, the age-related network modulation, and its possible functional relevance, will be discussed in more detail (Section 4.3).

\subsection{Externally guided motor performance}

During externally guided coordination, feedback of the ongoing movements was represented by a moving dot on the screen and contained spatiotemporal information of the limb movements, resulting in higher performance accuracy and stability. It was shown previously, that such sensory-motor transformations for externally guided movements are mediated by the so-called "dorsal stream" (Goodale and Milner, 1992). Our observations are in general agreement with these findings as the hMT/V5+, the parietal areas along the intraparietal sulcus, and premotor cortex all showed significantly higher activation levels during externally guided as compared to internally guided coordination in both age groups. The hMT/V5+, which receives its input from V1 and V2, is known to be a major motion sensitive area (Sunaert et al., 1999; Tootell et al., 1995; Watson et al., 1993), sending projections to the parietal cortex (Boussaoud et al., 1990). The parietal cortex and, particularly, areas within the intraparietal sulcus, have strong connections to specific subregions in the premotor cortex, forming parallel parieto-premotor circuits, each serving a specific function in transforming sensory (visual) information into action (Rizzolatti et al., 1998; Wenderoth et al., 2006; Wise et al., 1997).

All the aforementioned areas were activated during externally guided coordination by the young and old group, implying that both relied on largely the same network/strategy to steer their movements by means of external (augmented) movement information. However, externally guided coordination also resulted in age-related differences: The old group exhibited bilateral activation in the VIPS and MDIPS, which was not observed in the younger controls. Such additional patterns of brain recruitment in elderly are generally consistent with other imaging studies in which age-related surplus activations have been observed during various simple (Heuninckx et al., 2005; Hutchinson et al., 2002; Mattay et al., 2002; Naccarato et al., 2006; Riecker et al., 2006; Ward and Frackowiak, 2003) and more complex motor tasks (Heuninckx et al., 2005), albeit in different brain areas. Activation in the VIPS and MDIPS during our externally guided motor task is not surprising since the brain areas in and around the intraparietal sulcus are known to serve as an interface between the perceptual and motor systems for controlling movements in space (Grefkes and Fink, 2005). Supposedly, both areas receive projections from neuronal populations in the posterior parietal and occipital cortex which respond strongly to visual stimuli, as well from superior parietal and frontal areas which are highly involved in motor control (Rizzolatti et al., 1998). The observed additional activation in the VIPS and MDIPS therefore might suggest a more pronounced processing of the visual feedback signal in the elderly to control the coordination pattern and support on-line error correction.

The young group exhibited higher activation in the right AIPA, and in the left postcentral sulcus (near left AIPA) for the internally as compared to the externally guided movements. By contrast, the elderly showed a strong response in these areas which remained nearly equally high during both feedback conditions The AIPA has previously been shown to play a crucial part in processing visual information to guide motor actions (Rice et al., 2006; Tunik et al., 2005). Moreover, a connectivity analysis indicated that this region increased its functional coupling with the dorsal precentral cortex when visual information was made available (Wenderoth et al., 2006). Remarkably, older subjects activated this region not only during the externally guided but also during the internally guided mode in the present study. This suggests less differentiation between both feedback modalities in the older subjects.

\subsection{Internally guided motor performance}

During internally guided coordination, movements were performed in the absence of visual feedback, i.e., the required movement pattern had to be performed with increased reliance on an internal representation and was solely controlled by means of somatosensory information. In the young subjects, producing internally guided as compared with externally guided movements resulted in higher involvement of the right frontal operculum, the left and right S2, and, near the midline, the SMA and CMA. The higher involvement of SMA and CMA during internally guided movements is in general agreement with the traditional link of these mesial premotor areas with the internal triggering of motor actions, as revealed by several neurophysiological and imaging studies (e.g., Debaere et al., 2003; Deiber et al., 1991; Jenkins et al., 2000; Ogawa et al., 2006; Rao et al., 1997). Also the involvement of the frontal operculum and S2 has previously been observed during internally guided movements (Debaere et al., 2003; Weeks et al., 2001). Both interconnected regions are involved in the integration of somatosensory information to guide motor actions (Binkofski et al., 2000; Huttunen et al., 1996; Iacoboni et al., 1999; Matelli et al., 1986).

From the barplots in Fig. 4, it can be inferred that the aforementioned regions were involved during both internally and externally guided movements in the younger subjects, but 
displayed significantly higher activation during the internally guided mode. Presumably, these brain regions contribute to both modes, but their degree of involvement is modality dependent. Remarkably, these regions were strongly activated at comparable activation levels during both modalities in the seniors. These results point again towards a reduction of modality specificity in older adults. We hypothesize that the reduced differentiation between both feedback modalities reflects a general increase in processing resources within areas contributing to motor control and associated sensory processing, supporting performance in the elderly, as discussed in more detail next.

\subsection{Age-related reduction in modality specific activation}

Taken together, performing cyclical hand-foot coordination in the presence and absence of augmented visual feedback resulted in the activation of two distinct neural networks in the young adults, i.e., the hMT/V5+, and parietal and premotor cortices were typically involved during the externally guided performance mode, whereas the SMA, CMA, frontal operculum and S2 were involved during internally guided movements. These results are in excellent agreement with previous experiments in adolescents. Remarkably, there was much less differentiation between both feedback dependent networks in the seniors. More specifically, the seniors exhibited high activity in the SMA, CMA, frontal operculum and S2 during both the externally and internally guided mode, suggesting that the typical network differentiation was diminished in older subjects. A similar loss of specialization in the elderly brain has previously been shown for non-motor tasks. For example, younger adults exhibited anatomically and functionally separable peaks of activation when passively seeing faces, places and words, whereas older adults showed less differentiation of such material-specific subregions, activating all regions of interest, regardless of the type of material (Park et al., 2004). Similarly, Grady (2002) reported taskspecific activity in the prefrontal cortex during three different face processing experiments (episodic memory, working memory, and degraded face perception) in younger adults, whereas the older adults showed less task-specific regional differentiation.

Many functional imaging studies have revealed that elderly often exhibit "over-activation" as compared to younger subjects. Traditionally, these results have been interpreted in view of the compensation versus dedifferentiation hypothesis. Compensatory "over-activation" supports performance, whereas dedifferentiation is argued to reflect deficits in neurotransmission, which in turn cause decreases in signalto-noise ratio and less distinct neural representations (Grady, 2002; Li et al., 2001; Park et al., 2004). Additionally, dedifferentiation has been considered to result in aberrant and dysfunctional neural activity that is irrelevant or even detrimental to task performance.
In our study, we found an age-related reduction in network dissociation, indicating a 'de-differentiation' or reduced specialization of functional networks in the elderly. However, contrary to the view that de-differentiation is dysfunctional by definition, we propose that the age-related reduction in modality-specific activation in our task was most likely functional and benefited task performance (see also Rajah and D'Esposito, 2005). There are at least two reasons to justify this perspective. First, our behavioral data clearly showed that providing visual feedback improved performance. Moreover, previous work using more complex tasks (Seidler-Dobrin and Stelmach, 1998; van Hedel and Dietz, 2004; Wishart et al., 2002) has demonstrated that visual feedback even results in an overproportional benefit in the elderly as compared to young subjects. Second, the SMA, CMA, frontal operculum and S2 are known to be involved in the integration of somatosensory information to guide motor actions (see above), and, as such, serve an important function in the context of our task in which somatosensory information from different effectors has to be mapped onto each other to achieve successful coordination. Consequently, age-related overactivation in these regions likely reflects an increasing recruitment of computational resources within task-related areas. This view is also in agreement with other studies, showing that successful elderly exhibit more extended brain activation than elderly performing badly (Cabeza et al., 2002; Grady et al., 2003; Heuninckx et al., 2008; Madden et al., 2004; Mattay et al., 2002; Rosen et al., 2002; Scarmeas et al., 2003), indicating that age-related changes in brain activity patterns may benefit behavior. Therefore, we hypothesize that the observed reduction in network differentiation in the older adults reflects a general age-dependent upscaling of processing resources within areas contributing to motor control and associated sensory processing.

\subsection{Summary and conclusions}

The present study addressed for the first time age-related changes in the neural control of cyclical hand-foot coordination patterns in the presence and absence of augmented visual feedback. Consistent with earlier reports, performance under both feedback modes resulted in the activation of two distinct neural networks in the young adults. However, much less differentiation between both feedback-dependent networks was observed in the seniors. To the best of our knowledge, this represents a new observation in the context of movement generation networks. The activation of these non-vision specific areas is suggested to aid performance in elderly by upscaling computational resources within areas (in)directly contributing to motor control and associated sensory processing. It is unclear, however, whether this reduction of modality-specific activation in movement generation networks reflects a compensatory mechanism, which is regulated by top-down control, or a self-emerging property. In this respect, it is tempting to speculate that dedifferentiation serves to increase the accessibility of interconnected brain 
regions to keep the aging brain functional in a self-organizing manner.

\section{Disclosure}

All authors confirm that they have no financial, actual or potential, conflicts of interest that could inappropriately influence or bias this work.

\section{Acknowledgements}

Support for this study was provided through a grant from the Research Council of K.U.Leuven, Belgium (Contract OT/07/073) and the Flanders Fund for Scientific Research (Projects G.0460.04 \& G.0105.00). This work was also supported by Grant P6/29 from the Interuniversity Attraction Poles program of the Belgian federal government. Heuninckx S. is funded by a fellowship from F.W.O. Vlaanderen.

\section{Appendix A. Supplementary data}

Supplementary data associated with this article can be found, in the online version, at doi:10.1016/j.neurobiolaging. 2008.03.021.

\section{References}

Baldissera, F., Cavallari, P., Civaschi, P., 1982. Preferential coupling between voluntary movements of ipsilateral limbs. Neurosci. Lett. 34, 95-100.

Binkofski, F., Amunts, K., Stephan, K.M., Posse, S., Schormann, T., Freund, H.J., Zilles, K., Seitz, R.J., 2000. Broca's region subserves imagery of motion: a combined cytoarchitectonic and fMRI study. Hum. Brain Mapp. 11, 273-285.

Boussaoud, D., Ungerleider, L.G., Desimone, R., 1990. Pathways for motion analysis: cortical connections of the medial superior temporal and fundus of the superior temporal visual areas in the macaque. J. Comp. Neurol. 296, 462-495

Cabeza, R., 2001. Cognitive neuroscience of aging: contributions of functional neuroimaging. Scand. J. Psychol. 42, 277-286.

Cabeza, R., Anderson, N.D., Locantore, J.K., McIntosh, A.R., 2002. Aging gracefully: compensatory brain activity in high-performing older adults. NeuroImage 17, 1394-1402.

Carson, R.G., Goodman, D., Kelso, J.A., Elliott, D., 1995. Phase transitions and critical fluctuations in rhythmic coordination of ipsilateral hand and foot. J. Mot. Behav. 27, 211-224.

Debaere, F., Wenderoth, N., Sunaert, S., Van Hecke, P., Swinnen, S.P., 2003. Internal vs. external generation of movements: differential neural pathways involved in bimanual coordination performed in the presence or absence of augmented visual feedback. NeuroImage 19, 764-776.

Deiber, M.P., Honda, M., Ibanez, V., Sadato, N., Hallett, M., 1999. Mesial motor areas in self-initiated versus externally triggered movements examined with fMRI: effect of movement type and rate. J. Neurophysiol. 81, 3065-3077.

Deiber, M.P., Passingham, R.E., Colebatch, J.G., Friston, K.J., Nixon, P.D. Frackowiak, R.S., 1991. Cortical areas and the selection of movement: a study with positron emission tomography. Exp. Brain. Res. 84, 393-402.
Folstein, M.F., Folstein, S.E., McHugh, P.R., 1975. Mini-mental state. A practical method for grading the cognitive state of patients for the clinician. J. Psychiatr. Res. 12, 189-198.

Friston, K.J., Holmes, A.P., Poline, J.B., Grasby, P.J., Williams, S.C., Frackowiak, R.S., Turner, R., 1995a. Analysis of fMRI time-series revisited. NeuroImage 2, 45-53.

Friston, K., Holmes, A., Worsley, K., Poline, J., Frith, C., Frackowiak, R., 1995b. Statistical parametric maps in functional imaging: a general linear approach. Hum. Brain Mapp. 2, 189-210.

Genovese, C.R., Lazar, N.A., Nichols, T., 2002. Thresholding of statistical maps in functional neuroimaging using the false discovery rate. NeuroImage 15, 870-878.

Goldberg, G., 1985. Supplementary motor area structure and function: review and hypothesis. Behav. Brain Sci. 8, 567-616.

Goodale, M.A., Milner, A.D., 1992. Separate visual pathways for perception and action. Trends Neurosci. 15, 20-25.

Grady, C.L., 2000. Functional brain imaging and age-related changes in cognition. Biol. Psychol. 54, 259-281.

Grady, C.L., 2002. Age-related differences in face processing: a metaanalysis of three functional neuroimaging experiments. Can. J. Exp. Psychol. 56, 208-220.

Grady, C.L., McIntosh, A.R., Beig, S., Keightley, M.L., Burian, H., Black, S.E., 2003. Evidence from functional neuroimaging of a compensatory prefrontal network in Alzheimer's disease. J. Neurosci. 23, 986993.

Grefkes, C., Fink, G.R., 2005. The functional organization of the intraparietal sulcus in humans and monkeys. J. Anat. 207, 3-17.

Hedden, T., Gabrieli, J.D., 2004. Insights into the ageing mind: a view from cognitive neuroscience. Nat. Rev. Neurosci. 5, 87-96.

Heuninckx, S., Wenderoth, N., Debaere, F., Peeters, R., Swinnen, S.P., 2005. Neural basis of aging: the penetration of cognition into action control. J. Neurosci. 25, 6787-6796.

Heuninckx, S., Wenderoth, N., Swinnen, S.P., 2008. Systems neuroplasticity in the aging brain: recruiting additional neural resources for successful motor performance in elderly persons. Neurosci. J. 28, 91-99.

Hutchinson, S., Kobayashi, M., Horkan, C.M., Pascual-Leone, A., Alexander, M.P., Schlaug, G., 2002. Age-related differences in movement representation. NeuroImage 17, 1720-1728.

Huttunen, J., Wikstrom, H., Korvenoja, A., Seppalainen, A.M., Aronen, H., Ilmoniemi, R.J., 1996. Significance of the second somatosensory cortex in sensorimotor integration: enhancement of sensory responses during finger movements. Neuroreport 7, 1009-1012.

Iacoboni, M., Woods, R.P., Brass, M., Bekkering, H., Mazziotta, J.C., Rizzolatti, G., 1999. Cortical mechanisms of human imitation. Science 286, 2526-2528.

Jenkins, I.H., Jahanshahi, M., Jueptner, M., Passingham, R.E., Brooks, D.J., 2000. Self-initiated versus externally triggered movements. II. The effect of movement predictability on regional cerebral blood flow. Brain 123, $1216-1228$

Jueptner, M., Weiller, C., 1998. A review of differences between basal ganglia and cerebellar control of movements as revealed by functional imaging studies. Brain 121, 1437-1449.

Lee, T.D., Swinnen, S.P., Verschueren, S., 1995. Relative phase alterations during bimanual skill acquisition. J. Mot. Behav. 27, 263-274.

Li, S.C., Lindenberger, U., Sikstrom, S., 2001. Aging cognition: from neuromodulation to representation. Trends Cogn. Sci. 5, 479-486.

Madden, D.J., Whiting, W.L., Provenzale, J.M., Huettel, S.A., 2004. Agerelated changes in neural activity during visual target detection measured by fMRI. Cereb. Cortex. 14, 143-155.

Matelli, M., Camarda, R., Glickstein, M., Rizzolatti, G., 1986. Afferent and efferent projections of the inferior area 6 in the macaque monkey. J. Comp. Neurol. 251, 281-298.

Mattay, V.S., Fera, F., Tessitore, A., Hariri, A.R., Das, S., Callicott, J.H., Weinberger, D.R., 2002. Neurophysiological correlates of age-related changes in human motor function. Neurology 58, 630-635.

Naccarato, M., Calautti, C., Jones, P.S., Day, D.J., Carpenter, T.A., Baron, J.C., 2006. Does healthy aging affect the hemispheric activation bal- 
ance during paced index-to-thumb opposition task? An fMRI study. NeuroImage 32, 1250-1256.

Nichols, T., Brett, M., Andersson, J., Wager, T., Poline, J.B., 2005. Valid conjunction inference with the minimum statistic. NeuroImage 25, 653-660.

Ogawa, K., Inui, T., Sugio, T., 2006. Separating brain regions involved in internally guided and visual feedback control of moving effectors: an event-related fMRI study. NeuroImage 32, 1760-1770.

Oldfield, R.C., 1971. The assessment and analysis of handedness: the Edinburgh inventory. Neuropsychologia 9, 97-113.

Park, D.C., Polk, T.A., Park, R., Minear, M., Savage, A., Smith, M.R., 2004. Aging reduces neural specialization in ventral visual cortex. Proc. Natl. Acad. Sci. U.S.A. 101, 13091-13095.

Passingham, R., 1997. The Frontal Lobes and Voluntary Action. Oxford University Press, Oxford.

Rajah, M.N., D'Esposito, M., 2005. Region-specific changes in prefrontal function with age: a review of PET and fMRI studies on working and episodic memory. Brain 128, 1964-1983.

Rao, S.M., Harrington, D.L., Haaland, K.Y., Bobholz, J.A., Cox, R.W., Binder, J.R., 1997. Distributed neural systems underlying the timing of movements. J. Neurosci. 17, 5528-5535.

Reuter-Lorenz, P., 2002. New visions of the aging mind and brain. Trends Cogn. Sci. 6, 394.

Reuter-Lorenz, P.A., Lustig, C., 2005. Brain aging: reorganizing discoveries about the aging mind. Curr. Opin. Neurobiol. 15, 245-251.

Rice, N.J., Tunik, E., Grafton, S.T., 2006. The anterior intraparietal sulcus mediates grasp execution, independent of requirement to update: new insights from transcranial magnetic stimulation. J. Neurosci. 26, 28176-28182.

Riecker, A., Groschel, K., Ackermann, H., Steinbrink, C., Witte, O., Kastrup, A., 2006. Functional significance of age-related differences in motor activation patterns. NeuroImage 32, 1345-1354.

Rizzolatti, G., Luppino, G., Matelli, M., 1998. The organization of the cortical motor system: new concepts. Electroencephalogr. Clin. Neurophysiol. 106, 283-296.

Rosen, A.C., Prull, M.W., O'Hara, R., Race, E.A., Desmond, J.E., Glover, G.H., Yesavage, J.A., Gabrieli, J.D., 2002. Variable effects of aging on frontal lobe contributions to memory. Neuroreport 13, 2425-2428.

Scarmeas, N., Zarahn, E., Anderson, K.E., Hilton, J., Flynn, J., Van Heertum, R.L., Sackeim, H.A., Stern, Y., 2003. Cognitive reserve modulates functional brain responses during memory tasks: a PET study in healthy young and elderly subjects. NeuroImage 19, 1215-1227.

Seidler, R.D., Stelmach, G.E., 1995. Reduction in sensorimotor control with age. Quest 47, 386-394.

Seidler-Dobrin, R.D., Stelmach, G.E., 1998. Persistence in visual feedback control by the elderly. Exp. Brain. Res. 119, 467-474.

Spirduso, W.W., 1982. Physical fitness in relation to motor aging. In: Mortimer, J.A., Pirozzolo, F.J.M.G.J. (Eds.), The Aging Motor System. Prager, New York, pp. 120-151.

Sunaert, S., Van Hecke, P., Marchal, G., Orban, G.A., 1999. Motionresponsive regions of the human brain. Exp. Brain. Res. 127, 355370.
Swinnen, S., Jardin, K., Meulenbroek, R., Dounskaia, N., Hofkens-Van Den Brandt, M., 1997a. Egocentric and allocentric constraints in the expression of patterns of interlimb coordination. J. Cogn. Neurosci. 9 , 348-377.

Swinnen, S.P., Lee, T.D., Verschueren, S., Serrien, D.J., Bogaerts, H., 1997b. Interlimb coordination: learning and transfer under different feedback conditions. Hum. Mov. Sci. 16, 749-785.

Swinnen, S.P., Verschueren, S.M.P., Bogaerts, H., Dounskaia, N., Lee, T.D., Stelmach, G.E., Serrien, D.J., 1998. Age-related deficits in motor learning and differences in feedback processing during the production of a bimanual coordination pattern. Cogn. Neuropsychol. 15, 439-466.

Talairach, J., Tournoux, P., 1988. Co-planar Stereotaxic Atlas of the Human Brain. Thieme, New York.

Tootell, R.B., Reppas, J.B., Dale, A.M., Look, R.B., Sereno, M.I., Malach, R., Brady, T.J., Rosen, B.R., 1995. Visual motion aftereffect in human cortical area MT revealed by functional magnetic resonance imaging. Nature 375, 139-141.

Tunik, E., Frey, S.H., Grafton, S.T., 2005. Virtual lesions of the anterior intraparietal area disrupt goal-dependent on-line adjustments of grasp. Nat. Neurosci. 8, 505-511.

Vaillancourt, D.E., Thulborn, K.R., Corcos, D.M., 2003. Neural basis for the processes that underlie visually guided and internally guided force control in humans. J. Neurophysiol. 90, 3330-3340.

van Donkelaar, P., Stein, J.F., Passingham, R.E., Miall, R.C., 1999. Neuronal activity in the primate motor thalamus during visually triggered and internally generated limb movements. J. Neurophysiol. 82, 934945.

van Hedel, H.J., Dietz, V., 2004. The influence of age on learning a locomotor task. Clin. Neurophysiol. 115, 2134-2143.

Ward, N.S., Frackowiak, R.S., 2003. Age-related changes in the neural correlates of motor performance. Brain 126, 873-888.

Ward, N.S., 2006. Compensatory mechanisms in the aging motor system. Ageing Res. Rev. 5, 239-254.

Watson, J.D., Myers, R., Frackowiak, R.S., Hajnal, J.V., Woods, R.P., Mazziotta, Shipp, S., Zeki, S., 1993. Area V5 of the human brain: evidence from a combined study using positron emission tomography and magnetic resonance imaging. Cereb. Cortex. 3, 79-94.

Weeks, R.A., Honda, M., Catalan, M.J., Hallett, M., 2001. Comparison of auditory, somatosensory, and visually instructed and internally generated finger movements: a PET study. NeuroImage 14, 219-230.

Welford, A.T., 1988. Reaction time, speed of performance, and age. Ann. N.Y. Acad. Sci. 515, 1-17.

Wenderoth, N., Toni, I., Bedeleem, S., Debaere, F., Swinnen, S.P., 2006. Information processing in human parieto-frontal circuits during goaldirected bimanual movements. NeuroImage 31, 264-278.

Wise, S.P., Boussaoud, D., Johnson, P.B., Caminiti, R., 1997. Premotor and parietal cortex: corticocortical connectivity and combinatorial computations. Annu. Rev. Neurosci. 20, 25-42.

Wishart, L.R., Lee, T.D., Cunningham, S.J., Murdoch, J.E., 2002. Agerelated differences and the role of augmented visual feedback in learning a bimanual coordination pattern. Acta Psychol. 110, 247-263. 